\title{
Incidence du niveau protéique de l'aliment, du milieu d'élevage et de la saison sur la croissance et les qualités bouchères du lapin
}

\author{
F. LEBAS, J. OUHAYOUN \\ INRA, Laboratoire de Recherches sur l'Elevage du Lapin \\ Centre de Recherches de Toulouse, B.P. 27, 31326 Castanet Tolosan Cedex
}

\section{Résumé}

352 lapins ont été engraissés entre 28 et 77 jours, dans des cages collectives réparties selon un schéma factoriel dans lequel les facteurs contrôlés sont les suivants : taux protéique de l'aliment ( 15,7 et $21,0 \%$ de la MS), milieu d'élevage (intérieur et extérieur) et saison (été et hiver). La moitié d'entre eux a été abattue en fin d'essai, en vue d'étudier les qualités bouchères.

La vitesse de croissance est améliorée par l'augmentation de la teneur en protéines de l'aliment $(+2,4 \mathrm{~g} / \mathrm{j})$, et par un abaissement de la température ambiante obtenu soit par l'élevage à l'extérieur $(+1,3 \mathrm{~g} / \mathrm{j})$, soit l'hiver $(+2,1 \mathrm{~g} / \mathrm{j})$. Dans ces deux derniers cas, l'indice de consommation est significativement amélioré. Le rendement à l'abattage est supérieur avec le taux protéique alimentaire le plus élevé $(+1,03 \%)$, chez les lapins élevés l'été $(+0,75 \%)$ ou à l'intérieur $(+0,35 \%)$. Dans les trois cas, l'amélioration du rendement est particulièrement attribuable à la diminution du poids relatif de la peau. L'adiposité périrénale des carcasses est réduite chez les lapins dont la croissance est ralentie par un faible niveau protéique dans l'aliment, ou une température élevée (élevage en intérieur ou l'été). La plupart des caractères de croissance et de composition corporelle sont soumis à l'interaction des facteurs de variation mis en œuvre. La réduction de l'adiposité est accompagnée d'une augmentation de la polyinsaturation des lipides corporels, attribuable à une diminution de la lipogénèse endogène.

Les résultats suggèrent que, pour obtenir à une température élevée une vitesse de croissance identique à celle obtenue à faible température, l'aliment doit être enrichi en protéines par rapport à l'énergie digestible.

Mots clés : Lapin, viande, protéines alimentaires, élevage, saison.

\section{Introduction}

L'influence du niveau azoté de la ration alimentaire sur les performances productives et les qualités bouchères du Lapin a fait l'objet d'un assez grand nombre de travaux. Une réduction de l'apport protéique en dessous des recommandations (INRA, 1984) altère la vitesse de croissance et les qualités bouchères. L'élevage des lapins en dehors d'un bâtiment entraîne une surconsommation d'aliment, par rapport à l'élevage à l'intérieur, pour une même vitesse de croissance (LeBAs, $1983 \mathrm{a}$ ). Par ailleurs, une élévation de la température ambiante se traduit par une sous-consommation, accompa- 
gnée d'une altération de l'efficacité alimentaire et surtout de la vitesse de croissance (EвERHart, 1980). Il nous est apparu intéressant d'évaluer les effets conjoints du taux de protéines de l'aliment, du milieu d'élevage et de la saison, sur les performances de croissance et les qualités bouchères des lapins.

\section{Matériel et méthodes}

\section{A. Animaux}

Au total, 352 lapereaux de deux sexes, de races Néozélandaise et métis Néozélandais $\times$ Californien ont été placés dès l'âge de 28 jours dans des cages collectives, à raison de 4 ou 5 sujets par cage. Ils ont été répartis équitablement entre les 8 combinaisons du schéma factoriel expérimental.

\section{B. Schéma factoriel}

Deux aliments, dont les caractéristiques figurent au tableau 1, ont été distribués à volonté durant tout l'essai. Ils diffèrent essentiellement par le taux de protéines : $15,7 \%$ de la MS (pauvre) et $21,0 \%$ de la MS (riche). Les protéines alimentaires présentent des compositions en acides aminés essentiels comparables : lysine 4,3-4,6\%, acides aminés soufrés 3,9-3,8\%, thréonine 3,9-3,9\%, tryptophane 1,3-1,3\%. Chaque aliment a été distribué à la moitié des lapins. Ceux-ci ont été logés, soit à l'extérieur, soit dans un bâtiment conventionnel d'élevage intensif à ambiance contrôlée. L'expérimentation a été conduite durant l'été 1983 (du 21 juin au 30 août), puis l'hiver suivant (du 15 décembre au 9 février). Les conditions de température, résultant de la combinaison des facteurs milieu et saison, sont résumées au tableau 2.

\section{Caractères mesurés}

La croissance individuelle des lapins et la consommation alimentaire par cage ont été suivies par des contrôles hebdomadaires. A l'âge de 77 jours, la moitié des lapins a été abattue. Sur chacun des lapins les poids de la peau et de la carcasse commerciale ont été mesurés. Un échantillon représentatif de 48 lapins a fait l'objet d'une étude plus fine des caractéristiques bouchères des carcasses. La carcasse prête à cuire (PAC) correspond, dans cette expérimentation, à la carcasse commerciale sans les yeux ni l'ensemble trachée, cœur et poumons. L'adiposité a été estimée par pesée du gras périrénal et interscapulaire. Le développement relatif de la musculature et du squelette a été évalué par désossage d'un membre postérieur, élément anatomique représentatif de l'ensemble de la carcasse (VArewyck \& BouQuet, 1982). Enfin, la composition en acides gras des lipides de dépôt a été déterminée par analyse d'échantillons moyens de graisses périrénales et interscapulaires, représentatifs de chaque combinaison du plan factoriel $2 \times 2 \times 2$. 
TABllau 1

Caractéristiques des aliments expérimentaux.

Characteristics of experimental diets.

\begin{tabular}{|c|c|c|c|}
\hline \multirow[b]{2}{*}{ Composants } & \multirow[t]{2}{*}{$\begin{array}{c}\text { Pauvre } \\
\text { Low } \\
\text { Protein }\end{array}$} & \multirow[t]{2}{*}{$\begin{array}{c}\text { Riche } \\
\text { High } \\
\text { Protein }\end{array}$} & \\
\hline & & & Components \\
\hline Avoine & 15,0 & 15,0 & Oats \\
\hline Blé & 15,0 & 15,0 & Wheat \\
\hline Tourteau de soja & 4,5 & 11.0 & Soyabean meal \\
\hline Tourteau de tournesol & 2,0 & 5,5 & Sunflower meal \\
\hline Luzerne déshydratée & 46,9 & 46.9 & Dehydrated lucerne \\
\hline Paille de blé & 4,0 & 2.0 & Wheat straw \\
\hline Amidon de maïs & 9.5 & 1,5 & Maize starch \\
\hline dl méthionine & 0,1 & 0,1 & dl methionine \\
\hline Phosphate bicalcique & 1,5 & 1.5 & Dicalcium phosphate \\
\hline Chlorure de sodium & 0,5 & 0,5 & Sodium chloride \\
\hline Oligo-éléments et vitamines ${ }^{(1)}$ & 1,0 & 1,0 & Minerals and vitamins (1) \\
\hline Matière sèche $(\%)$ & 90,2 & 90,4 & Dry matter $(\%)$ \\
\hline Composition de la matière sèche & & & Dry matter composition \\
\hline Protéines brutes (\%) & 15,7 & 21,0 & Crude protein \\
\hline Energie brute (kcal/kg) & 4240 & 4370 & Gross energy \\
\hline Cellulose brute $(\%)$ & 14,2 & 14,2 & Crude fibre \\
\hline NDF $(\%)$ & 28,8 & 28,9 & $N D F$ \\
\hline ADF $(\%)$ & 16,5 & 16,6 & $A D F$ \\
\hline Lignine $(\%)$ & 3,7 & 4,0 & Lignine \\
\hline Matières grasses $(\%)$ & 2,3 & 2.5 & Lipids \\
\hline Lysine (calculée) $(\%)$ & 0,65 & 0.89 & Lysine (calculated) \\
\hline A.A. soufrés (calculés) $(\%)$ & 0,58 & 0.74 & Sulfur A.A. (calculated) \\
\hline \multicolumn{2}{|c|}{ Coefficients d'utilisation digestive apparente $(\%)$} & \multicolumn{2}{|c|}{ Apparent digestibility $(\%)$} \\
\hline Matière sèche & 63,8 & 63,6 & Dry matter \\
\hline Azote & 68.8 & 73,2 & Nitrogen \\
\hline Energie & 62,9 & 64,1 & Energy \\
\hline Cellulose brute & 16,5 & 16,8 & Crude fibre \\
\hline Eléments digestibles & & & Digestible components \\
\hline Energie digestible (kcal/kg) $E_{D}$ & 2669 & 2801 & Digestible energy $(\mathrm{kcal} / \mathrm{kg}) E_{D}$ \\
\hline Protéines digestibles $(\%) \mathrm{P}_{\mathrm{D}}$ & 10,80 & 15,37 & Digestible proteins $(\%) P_{n}$ \\
\hline $\mathrm{P}_{\mathrm{D}} / \mathrm{E}_{\mathrm{D}}(\mathrm{g} / 1000 \mathrm{kcal})$ & 40,5 & 54,9 & $P_{D} / E_{D}(\mathrm{~g} / 1000 \mathrm{kcal})$ \\
\hline
\end{tabular}

(1) SL 15 commercialisé par CCPA ; (1) SL 15 produced by CCPA.

\section{Analyse statistique}

Les calculs statistiques ont été réalisés sur l'ordinateur Mini 6 du Centre INRA de Toulouse, avec le programme d'analyse de variance factorielle, adapté au cas des effectifs déséquilibrés (programme ANVAR, BAcHacou et al., 1981). Le modèle statistique utilisé est généralement de la forme :

$$
\mathrm{Y}=\mu+\mathrm{A}+\mathrm{B}+\mathrm{C}+\mathrm{AB}+\mathrm{AC}+\mathrm{BC}
$$

où $\mu$ est la moyenne générale du caractère $Y ; A, B$ et $C$, respectivement, les estimées des effets des facteurs "protéines ", " milieu " et "saison"; AB, AC... les estimées des interactions de premier ordre. 
TABLEAU 2

Conditions de température (degré centésimal).

General conditions of temperature (centesimal degree).

\begin{tabular}{ll|c|c|c}
\hline \multirow{2}{*}{} & \multicolumn{3}{|c}{$\begin{array}{c}\text { Température } \\
\text { Temperature }\end{array}$} \\
\cline { 3 - 5 } & & $\begin{array}{c}\text { Moyenne } \\
\text { Mean }\end{array}$ & $\begin{array}{l}\text { Minimum } \\
\text { Minimum }\end{array}$ & $\begin{array}{c}\text { Maximum } \\
\text { Maximum }\end{array}$ \\
\cline { 3 - 5 } Eté & $\begin{array}{l}\text { intérieur } \\
\text { indoors } \\
\text { extérieur } \\
\text { outdoors }\end{array}$ & 26,0 & 20,7 & 33,0 \\
\hline Hiver & $\begin{array}{l}\text { intérieur } \\
\text { indoors } \\
\text { extérieur } \\
\text { Winter }\end{array}$ & 16,4 & 8,0 & 38,0 \\
\hline \hline
\end{tabular}

\section{Résultats}

\section{A. Performances de croissance (tabl. 3)}

La vitesse de croissance est plus grande chez les lapins recevant l'aliment riche en protéines, élevés à l'extérieur, ou l'hiver. Des interactions protéines $\times$ saison et milieu $\times$ saison sont observées. Ainsi, en été par exemple, le taux de protéines le plus faible et l'élevage à l'intérieur conduisent à une croissance encore plus lente $(-1,3=-0,7-0,6 \mathrm{~g} /$ j) que celle qui serait attendue de la seule influence des facteurs principaux. En revanche, l'hiver à l'intérieur, la vitesse de croissance observée avec ce même aliment pauvre est plus élevée $(+1,3 \mathrm{~g} / \mathrm{j})$ que celle qui résulterait de l'effet simple des facteurs principaux.

La consommation d'aliment varie dans le même sens que le gain de poids, en fonction des facteurs expérimentaux.

L'efficacité alimentaire n'est pas influencée par le niveau protéique de la ration. Elle est moins bonne en hiver et pour les lapereaux élevés à l'extérieur. L'existence d'une interaction milieu $\times$ saison aggrave les conséquences négatives de la combinaison « extérieur, hiver», et atténue l'effet favorable de la combinaison «intérieur, été ».

\section{B. Rendement à l'abattage (tabl. 4)}

L'abattage a eu lieu à 77 jours, à un poids moyen $(2,2 \mathrm{~kg})$ proche de l'optimum commercial. Les variations de ce poids en fonction des facteurs expérimentaux sont celles décrites ci-dessus à propos de la vitesse de croissance (effets principaux et interactions). 
TABLEAU 3

Performances de croissance moyennes et estimées des écarts dus aux différents facteurs expérimentaux.

Mean fattening performance and estimated deviations according to experimental factors.

\begin{tabular}{|c|c|c|c|c|c|c|c|}
\hline & & Effectif & $\begin{array}{l}\text { Poids } \\
\text { Live wt }\end{array}$ & & GMQ $(g / j)$ & $\begin{array}{c}\text { Consom. } \\
\text { aliment }(g j \mathrm{j})\end{array}$ & I.C. \\
\hline & & $\begin{array}{c}\text { Number of } \\
\text { data }\end{array}$ & $\begin{array}{l}28 \mathrm{j} \\
28 \mathrm{~d}\end{array}$ & $77 \mathrm{j}$ & $\begin{array}{l}\text { daily gain } \\
\text { (g/d) }\end{array}$ & $\begin{array}{l}\text { Feed } \\
\text { consumption } \\
(g / d)\end{array}$ & $\begin{array}{c}\text { efficiency } \\
(g / g)\end{array}$ \\
\hline $\begin{array}{l}\text { Mo } \\
\text { Ger }\end{array}$ & $\begin{array}{l}\text { yenne générale } \\
\text { eeral mean }\end{array}$ & 70 & 637 & 2188 & 31,7 & 107 & 3,34 \\
\hline $\begin{array}{l}\text { Pro } \\
\text { bru } \\
\text { Cru } \\
\text { Pro }\end{array}$ & $\begin{array}{ll}\text { téines } & \text { pauvre } \\
\text { tes } & \text { (low) } \\
\text { de } & \text { riche } \\
\text { tein } & \text { (high) } \\
\end{array}$ & $\begin{array}{l}35 \\
35\end{array}$ & $\begin{array}{l}-2 \\
+2\end{array}$ & $\begin{array}{l}-120 \\
+120\end{array}$ & $\begin{array}{l}-2,4^{* *} \\
+2,4^{2}\end{array}$ & $\begin{array}{l}-6 \\
+6\end{array}$ & $\begin{array}{l}+0,05 \\
-0,05\end{array}$ \\
\hline Mil & $\begin{array}{ll}\text { intérieur } \\
\text { indoors }\end{array}$ & 35 & & -66 & $-1,3_{* *}$ & $-10_{* *}$ & $-0,18$ \\
\hline Hot & ısing $\begin{array}{l}\text { extérieur } \\
\text { outdoors }\end{array}$ & 35 & +0 & +66 & $+1,3$ & +10 & $+0,18$ \\
\hline Sais & on été (summer) & 36 & $-43 * *$ & $-148_{* *}$ & $-2,1_{* *}$ & $-17_{* *}$ & $-0,32$ \\
\hline Sea & son hiver (winter) & 34 & +43 & +148 & $+2,1$ & +17 & $+0,32$ \\
\hline & $\begin{array}{l}\text { Protéines } \times \text { milieu } \\
\text { Protein } \times \text { housing }\end{array}$ & - & NS & NS & NS & NS & NS \\
\hline 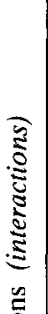 & $\begin{array}{l}\text { Protéines } \times \text { saison } \\
\text { Protein } \times \text { season } \\
\text { pauvre } \times \text { été } \\
\text { low } \times \text { summer } \\
\text { pauvre } \times \text { hiver } \\
\text { low } \times \text { winter } \\
\text { riche } \times \text { été } \\
\text { high } \times \text { summer } \\
\text { riche } \times \text { hiver } \\
\text { high } \times \text { winter }\end{array}$ & $\begin{array}{l}18 \\
17 \\
18 \\
17\end{array}$ & NS & NS & $\begin{array}{c}* \\
-0,7 \\
+0,7 \\
+0,7 \\
-0,7\end{array}$ & NS & NS \\
\hline 农 & $\begin{array}{l}\text { Milieu } \times \text { saison } \\
\text { Housing } \times \text { season } \\
\text { intérieur } \times \text { été } \\
\text { indoors } \times \text { summer } \\
\text { intérieur } \times \text { hiver } \\
\text { indoors } \times \text { winter } \\
\text { extérieur } \times \text { été } \\
\text { outdoors } \times \text { summer } \\
\text { extérieur } \times \text { hiver } \\
\text { outdoors } \times \text { winter }\end{array}$ & $\begin{array}{l}18 \\
17 \\
18 \\
17\end{array}$ & NS & NS & $\begin{array}{c}* \\
-0,6 \\
+0,6 \\
+0,6 \\
-0,6\end{array}$ & NS & $\begin{array}{c}* * \\
+0,10 \\
-0,10 \\
-0,10 \\
+0,10\end{array}$ \\
\hline & $\begin{array}{l}\text { rcentage de la variabi- } \\
\text { expliqué par le modèle } \\
\text { entage of variability } \\
\text { ained by model }\end{array}$ & - & 7,5 & 59,8 & 69,9 & 79,1 & 69,0 \\
\hline & $\begin{array}{l}\text { non significatif (non sig } \\
\text { significatif (significant) } \\
\text { hautement significatif }(h\end{array}$ & $\begin{array}{l}\text { t) } \mathrm{P}>0 \\
\mathrm{P}<0 \\
\text { ignific }\end{array}$ & 0.01 & & & & \\
\hline
\end{tabular}




\section{TABI.EAU 4}

Caractéristiques des lapins lors de l'abattage. Moyennes et estimées des écarts dus aux différents facteurs expérimentaux.

Mean slaughter performance and estimated deviations according to experimental factors.

\begin{tabular}{|c|c|c|c|c|c|}
\hline \multirow{2}{*}{\multicolumn{2}{|c|}{$\begin{array}{l}\text { Moyenne générale } \\
\text { General mean }\end{array}$}} & $\begin{array}{l}\text { Effectif } \\
\text { Number } \\
\text { of rabbits }\end{array}$ & $\begin{array}{l}\text { P. vif } \\
\text { abattage }(\mathrm{g}) \\
\text { Slaughter } \\
\text { weight }(\mathrm{g})\end{array}$ & $\begin{array}{c}\text { Peau \% P. vif } \\
\text { Skin/slaughter } \\
\text { weight } \\
\text { percentage }\end{array}$ & $\begin{array}{l}\text { Carcasse \% } \\
\text { P. vif } \\
\text { Carcass/ } \\
\text { slaughter } \\
\text { weight } \\
\text { percentage }\end{array}$ \\
\hline & & 176 & 2190 & 13,79 & 58,87 \\
\hline \multicolumn{2}{|c|}{$\begin{array}{ll}\text { Protéines } & \text { pauvre } \\
\text { brutes } & \text { low } \\
\text { Crude } & \text { riche } \\
\text { protein } & \text { high } \\
\end{array}$} & $\begin{array}{l}87 \\
89\end{array}$ & $\begin{array}{l}-117 \\
+115\end{array} * *$ & $\begin{array}{l}-0.19 \\
+0.19\end{array}$ & $\begin{array}{l}-1,06 \\
+1,03\end{array} *$ \\
\hline \multirow{2}{*}{\multicolumn{2}{|c|}{$\begin{array}{ll}\text { Milicu } & \begin{array}{l}\text { intéricur } \\
\text { indoors }\end{array} \\
\text { Housing } & \begin{array}{l}\text { extérieur } \\
\text { outdoors }\end{array}\end{array}$}} & 94 & $-68 \quad * *$ & $-0,44 \quad * *$ & $+0,35$ \\
\hline & & 82 & +78 & +0.50 & $-0,40$ \\
\hline \multicolumn{2}{|c|}{$\begin{array}{ll}\text { Saison } & \text { été (summer) } \\
\text { Season } & \text { hiver (winter) }\end{array}$} & $\begin{array}{r}100 \\
76\end{array}$ & $\begin{array}{r}-126 \\
+166\end{array} * *$ & $\begin{array}{r}-0.30 \\
+0.39\end{array}$ & $\begin{array}{l}+0.75 \\
-0,99\end{array}$ \\
\hline \multirow{3}{*}{ 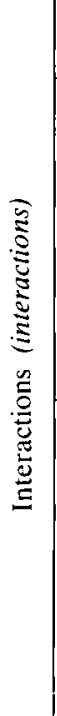 } & $\begin{array}{l}\text { Protéines } \times \text { milieu } \\
\text { Protein } \times \text { housing }\end{array}$ & - & NS & NS & NS \\
\hline & $\begin{array}{l}\text { Protéines } \times \text { saison } \\
\text { Protein } \times \text { season } \\
\text { pauvre } \times \text { été } \\
\text { low } \times \text { summer } \\
\text { pauvre } \times \text { hiver } \\
\text { low } \times \text { winter } \\
\text { riche } \times \text { ćté } \\
\text { high } \times \text { summer } \\
\text { riche } \times \text { hiver } \\
\text { high } \times \text { winter }\end{array}$ & $\begin{array}{l}- \\
50 \\
37 \\
50 \\
39\end{array}$ & $\begin{array}{c}* \\
-30 \\
+41 \\
+30 \\
-39\end{array}$ & $\begin{aligned} & * * \\
&- 0,18 \\
&+ 0.25 \\
&+ 0.18 \\
&-0.23\end{aligned}$ & $\begin{array}{c}* \\
-0,30 \\
+0.40 \\
+0,30 \\
-0,38\end{array}$ \\
\hline & $\begin{array}{l}\text { Milicu } \times \text { saison } \\
\text { Housing } \times \text { season } \\
\text { intérieur } \times \text { été } \\
\text { indoors } \times \text { summer } \\
\text { intérieur } \times \text { hiver } \\
\text { indoors } \times \text { winter } \\
\text { extćrieur } \times \text { été } \\
\text { outdoors } \times \text { summer } \\
\text { extérieur } \times \text { hiver } \\
\text { outdoors } \times \text { winter }\end{array}$ & $\begin{array}{l}- \\
54 \\
40 \\
46 \\
36\end{array}$ & $\begin{array}{l}* * \\
-55 \\
+75 \\
+65 \\
-83\end{array}$ & $\begin{array}{c}* * \\
+0,35 \\
-0,47 \\
-0.41 \\
+0.52\end{array}$ & NS \\
\hline \multicolumn{2}{|c|}{$\begin{array}{l}\text { Pourcentage de la variabi- } \\
\text { lité expliqué par le modèle } \\
\text { Percentage of variability } \\
\text { explained by model }\end{array}$} & - & 51,8 & 39,0 & 31,9 \\
\hline
\end{tabular}

NS. * et :** voir tableau 3 (see table 3). 
TABlEAU 5

Caractéristiques lors de labattage des lapins échantillonnés: moyennes générales et écarts dus aux différents facteurs expérimentaux.

Mean carcass characteristics and estimated deviations according to experimental factors.

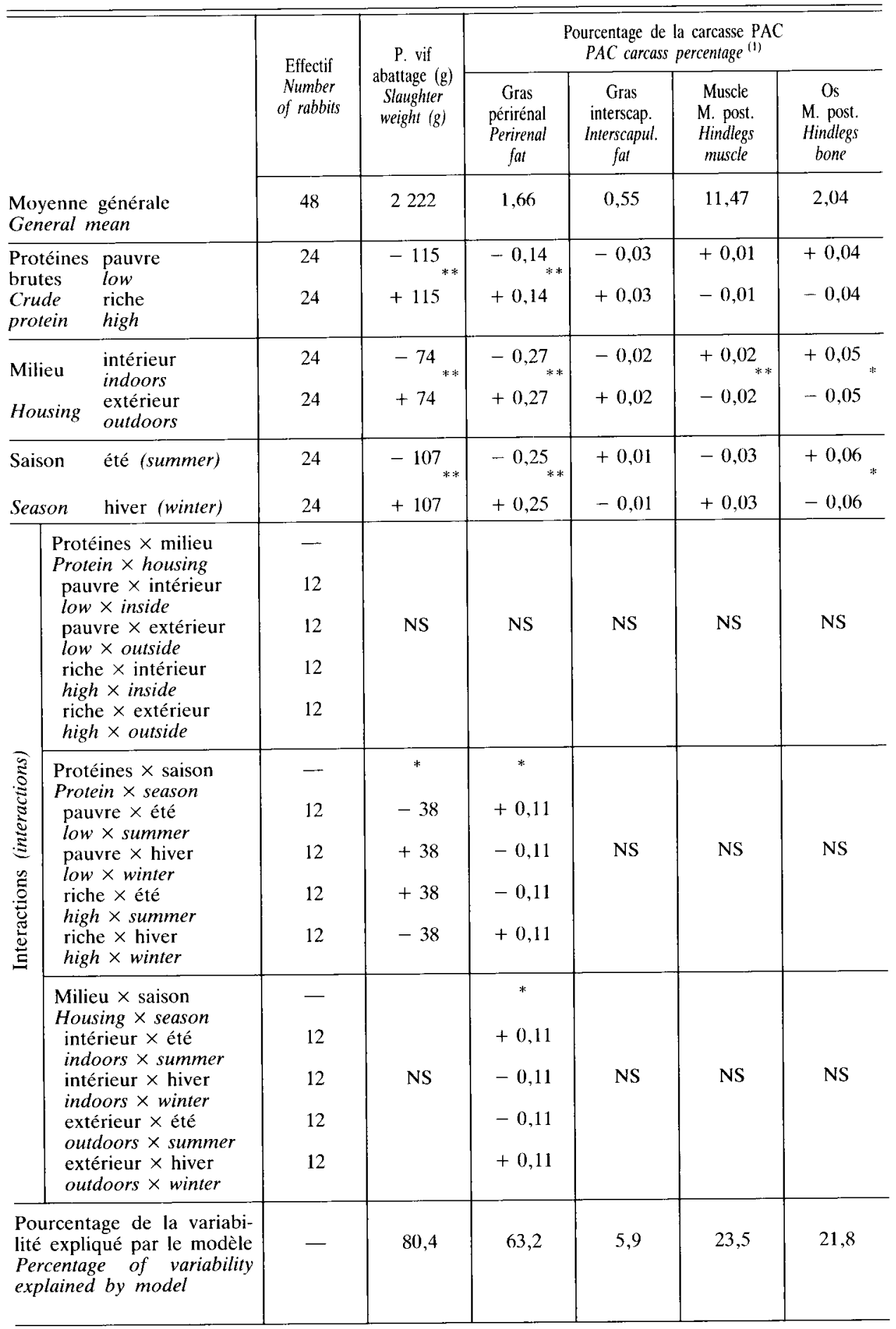


Le rendement à l'abattage est supérieur avec l'aliment riche en protéines, malgré l'accroissement du poids relatif de la peau. Bien que les lapins engraissés à l'intérieur ou en été soient les plus légers, leur rendement à l'abattage est élevé par suite d'une réduction de la proportion de peau, surtout chez les lapins élevés à l'intérieur. Les facteurs "protéines" et "saison" interagissent sur les performances d'abattage. Le rendement élevé obtenu en été avec l'aliment riche en protéines, bénéficie d'une interaction favorable. La combinaison "niveau bas de protéines ", " hiver " conduit à un rendement à l'abattage moins défavorable que celui qui serait attendu des effets principaux des facteurs.

\section{Qualité bouchère des carcasses (tabl. 5)}

Le poids vif à l'abattage des lapins échantillonnés pour l'analyse et l'étude des carcasses n'est pas différent de celui de la population des lapins abattus.

Les lapins les plus lourds, ceux qui ont reçu l'aliment riche en protéines, élevés à l'extérieur ou en hiver, sont significativement plus gras au niveau périrénal. Par contre, l'adiposité interscapulaire n'est pas modifiée de manière significative. L'interaction protéines $\times$ saison sur l'adiposité périrénale est positive, chez les lapins alimentés avec un niveau protéique élevé l'été ; en revanche, chez les lapins recevant l'aliment pauvre en protéines l'été, l'adiposité périrénale est plus forte que celle attendue des effets principaux. L'interaction milieu $\times$ saison conduit à des effets de même ampleur et de même sens que ceux dus à l'interaction protéines $\times$ saison décrite ci-dessus.

Bien qu'il modifie la croissance et le rendement à l'abattage, le taux protéique de la ration n'intervient pas de manière significative sur les proportions de muscle et d'os de la carcasse. Par contre, les lapins élevés à l'intérieur ont des proportions de muscle et d'os accrues. Par ailleurs, les lapins engraissés en été ont un squelette légèrement plus développé.

\section{Composition en acides gras des lipides des graisses de dépôt (tabl. 6)}

La composition en acides gras des lipides est peu sensible aux facteurs de variation mis en œuvre, qu'il s'agisse du tissu adipeux périrénal ou du tissu adipeux interscapulaire. Lorsqu'ils sont significatifs, les écarts sont faibles. Avec l'aliment pauvre en protéines, les taux des acides gras saturés sont accrus aux dépens des acides gras monoet polyinsaturés, en particulier de l'acide palmitoléique. Le milieu d'élevage n'a pas d'influence sur la composition des lipides. Par contre, les lipides des lapins élevés en été sont plus riches en acides gras polyinsaturés (acide linoléique en particulier) et moins riches en acides palmitique et monoinsaturé, d'origine endogène.

\section{Discussion}

L'expérimentation confirme l'influence du taux de protéines alimentaires sur la vitesse de croissance (LeBAs, 1983 a). Celle-ci est accélérée avec le taux protéique élevé, ce qui se traduit logiquement par un rendement à l'abattage amélioré et une adiposité plus forte de la carcasse (Martina et al., 1974 ; Ouhayoun \& Cheriet, 1983). 
TABleau 6

Composition en acides gras des lipides des graisses de dépôt. Moyenne générale et écarts dus aux différents facteurs expérimentaux.

Mean fatty acid composition of body fat and estimated deviations according to experimental factors.

\begin{tabular}{|c|c|c|c|c|c|c|c|c|c|}
\hline & \multirow{2}{*}{ 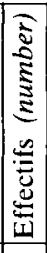 } & \multicolumn{7}{|c|}{ Acides gras (fatty acids) (\%) } \\
\hline & & & 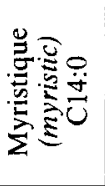 & 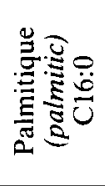 & 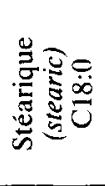 & 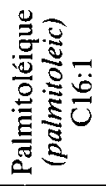 & 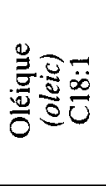 & 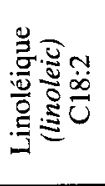 & 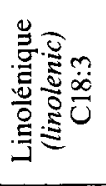 \\
\hline \multicolumn{2}{|c|}{$\begin{array}{l}\text { Moyenne générale } \\
\text { General mean }\end{array}$} & 16 & 3,2 & 29,6 & 6,7 & 3,8 & 29,7 & 18,6 & 5,7 \\
\hline $\begin{array}{l}\text { Protéines } \\
\text { brutes } \\
\text { Crude } \\
\text { protein }\end{array}$ & $\begin{array}{l}\text { pauvre } \\
\text { low } \\
\text { riche } \\
\text { high }\end{array}$ & $\begin{array}{l}8 \\
8\end{array}$ & $\begin{array}{l}+0,2 \\
-0,2\end{array}$ & $\begin{array}{l}+1,0 \\
-* * \\
-1,0\end{array}$ & $\begin{array}{l}+0,2 \\
-0,2\end{array}$ & $\begin{array}{l}-0,4 \\
+0,4\end{array}$ & $\begin{array}{l}-0,5 \\
+0,5\end{array}$ & $\begin{array}{r}-0,5 \\
+0,5\end{array}$ & $\begin{array}{l}-0,2 \\
+0,2\end{array}$ \\
\hline Milieu & $\begin{array}{l}\text { intérieur } \\
\text { indoors }\end{array}$ & 8 & $+0,0$ & $-0,0$ & $+0,1$ & $-0,1$ & $-0,5$ & $+0,4$ & $-0,0$ \\
\hline Housing & $\begin{array}{l}\text { extérieur } \\
\text { outdoors }\end{array}$ & 8 & $-0,0$ & $+0,0$ & $-0,1$ & $+0,1$ & $+0,5$ & $-0,4$ & $+0,0$ \\
\hline Saison & $\begin{array}{l}\text { été } \\
\text { summer }\end{array}$ & 8 & $+0,1$ & $-0,9$ & $-0,0$ & $-0,5$ & $-1,6$ & $+2,3$ & $+\underset{* *}{0,4}$ \\
\hline Season & $\begin{array}{l}\text { hiver } \\
\text { winter }\end{array}$ & 8 & $-0,1$ & $+0,9$ & $+0,0$ & $+0,5$ & $+1,6$ & $-2,3$ & $-0,4$ \\
\hline $\begin{array}{l}\text { Localisation } \\
\text { tissus gras }\end{array}$ & $\begin{array}{l}\text { rénal } \\
\text { kidneys }\end{array}$ & 8 & $\begin{array}{r}-0,2 \\
* *\end{array}$ & $-0,1$ & $\begin{array}{r}-0,5 \\
* *\end{array}$ & $+0,2$ & $+0,3$ & $+0,2$ & $+0,2$ \\
\hline $\begin{array}{l}\text { Location of } \\
\text { body fat }\end{array}$ & $\begin{array}{l}\text { scapulaire } \\
\text { shoulders }\end{array}$ & 8 & $+0,2$ & $+0,1$ & +0.5 & $-0,2$ & $-0,3$ & $-0,2$ & $-0,2$ \\
\hline $\begin{array}{l}\text { Pourcentage } \\
\text { lité expliqu } \\
\text { Percentage } \\
\text { explained } b\end{array}$ & $\begin{array}{l}\text { de la variabi- } \\
\text { par le modèle } \\
\text { of variability } \\
\text { model }\end{array}$ & - & 60,2 & 71,3 & 63,0 & 52,3 & 52,9 & 79,4 & 54,8 \\
\hline
\end{tabular}

NS, ${ }^{*} \mathrm{ct}{ }^{* *}$ : voir tablcau 3 (see table 3).

Les effets de la saison et du milieu d'élevage sur les performances de croissance peuvent être, en grande partie, expliqués par la température ambiante subie par les lapereaux durant leur engraissement. Cette température est plus faible à l'extérieur aussi bien en été qu'en hiver; elle est également moins stable. La différence entre les températures moyennes des milieux d'élevage, deux saisons confondues, est de $7{ }^{\circ} \mathrm{C}$ $\left(21,2\right.$ vs $\left.14,2^{\circ} \mathrm{C}\right)$; l'écart entre les vitesses de croissance des lapins est de $2,6 \mathrm{~g} /$ jour. Entre saisons, l'écart de température est plus important : $12,6^{\circ} \mathrm{C}\left(24,0\right.$ vs $\left.11,4^{\circ} \mathrm{C}\right)$, qu'entre milieux ; la différence entre les vitesses de croissance est également accrue et atteint $4,2 \mathrm{~g}$ /jour. L'influence de la température sur la consommation et l'efficacité alimentaire est similaire à celle qui est observée sur la vitesse de croissance : meilleure efficacité alimentaire dans le milieu le plus chaud, associée à une réduction de la consommation. 
La réduction du poids à 77 jours des lapins engraissés dans l'ambiance la plus chaude s'accompagne d'une réduction de poids relatif de la peau. On sait en effet que chez des lapins abattus à âge fixe, les sujets les plus légers ont une peau relativement moins développée (Ounayoun, 1978). Il est possible que cette réduction du poids relatif de la peau soit également due à une modification de la thermorégulation. La réduction de la proportion de peau entraine une augmentation du rendement à l'abattage, ce qui n'était pas attendu (Ouhayoun, 1978 ; Cheriet, 1983).

L'élévation de la température du milieu d'élevage, comme la distribution d'un aliment pauvre en protéines, limitent la vitesse de croissance et dépriment l'adiposité des carcasses au niveau périrénal, mais pas au niveau interscapulaire. Dans une expérimentation antérieure, LeBAS (1983 b) avait observé une augmentation de l'adiposité interscapulaire chez les lapins élevés dans un milieu chaud, sans modification significative de l'adiposité périrénale. Ces résultats ne sont, en fait, pas contradictoires, car dans les deux cas, le rapport gras interscapulaire/gras périrénal est accru en milieu chaud.

La réduction de l'adiposité est accompagnée d'une augmentation de la polyinsaturation des lipides des graisses de dépôt (acides linoléique et linolénique), très probablement liée à la faible lipogénèse endogène. Ceci se manifeste par une réduction des teneurs en acides palmitique, stéarique et oléique. Cette modification de la proportion des acides gras se traduit par un abaissement du profil de fusion des graisses.

Quel que soit le niveau protéique de l'aliment, la vitesse de croissance est d'autant plus ralentie que la température est élevée. L'indice de consommation décroît aussi en fonction de la température ambiante, mais selon une cinétique différente (fig. 1). Etant

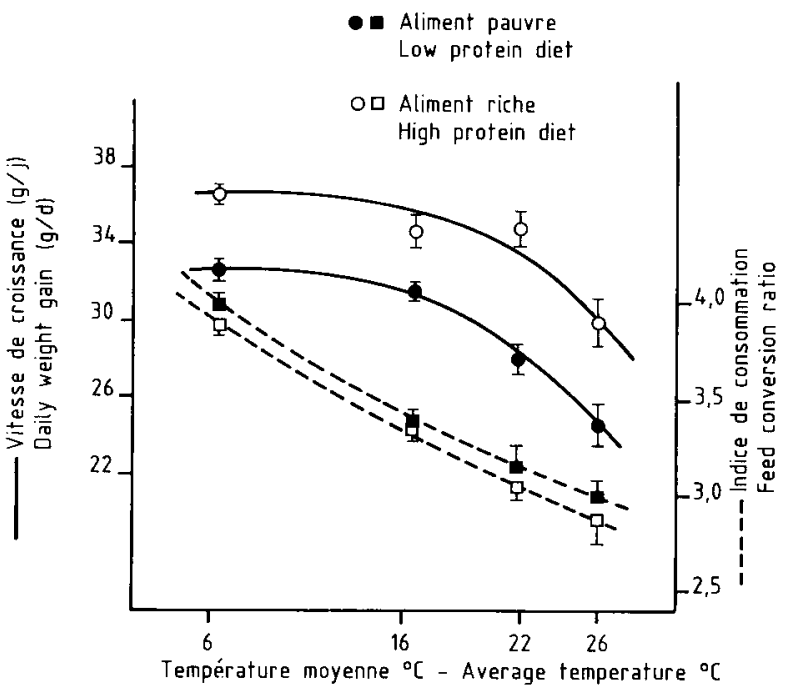

FIG. 1

Variations en fonction de la température moyenne, de la vitesse de croissance et de l'indice de consommation observé pour les 2 types d'aliment (moyenne et écart type de la moyenne). Variations, according to mean temperature, of growth rate and feed conversion ratio observed with two types of diet (mean and standard error of the mean). 
donné que l'ingestion d'aliment est ajustée par l'animal pour la satisfaction de ses besoins énergétiques, son ingestion décroît avec l'élévation de la température puisque ses besoins de thermogénèse sont moindres. Il en résulte une réduction de l'ingestion protéique. En conséquence, pour fournir à l’animal en engraissement la quantité de protéines permettant la vitesse de croissance attendue, il convient d'accroître la proportion des protéines par rapport à l'énergie digestible de l'aliment lorsque la température s'élève.

Reçu en décembre 1986.

Accepté en novembre 1987.

\section{Remerciements}

Les auteurs remercient C. JAmEt et l'équipe du Laboratoire de Recherches sur l'Elevage du Lapin pour leur participation à la réalisation de ce travail.

\section{Summary \\ Effect of dietary protein level, housing conditions and season on growth and slaughter traits of rabbits}

A total of 352 rabbits were fattened between 28 and 77 days of age in collective pens distributed according to a factorial design. The following variables were studied : dietary protein level (15.7 and $21.0 \%$ of DM) (table 1 ), housing conditions (indoors and outdoors) and season (summer and winter). Half of them were slaughtered at the end of the trial and their slaughter traits were studied.

Daily weight gain was improved by the dietary protein level $(+2.4 \mathrm{~g} / \mathrm{d})$ and by a reduction in the environmental temperature obtained either by outdoors $(+1.3 \mathrm{~g} / \mathrm{d})$ or winter rearing $(2.1 \mathrm{~g} / \mathrm{d})$. In the latter two cases, feed conversion ratio was significantly improved (table 3 ). Slaughter yield was higher with the higher dietary protein content $(+1.03 \%)$ in rabbits raised in summer $(+0.75 \%)$ or indoors $(+0.35 \%)$. In the three cases, the improved slaughter yield was mainly attributable to the decrease in the relative weight of the skin (table 4). Perirenal fat was reduced in rabbits exhibiting a slower growth rate due to a low dietary protein level or to a high environmental temperature (raising indoors or in summer) (table 5). Most growth and body composition traits were affected by the studied variables. The reduced fat content was accompanied by an increase in polyunsaturated lipids attributable to a decreased endogenous lipogenesis (table 6).

These results suggest that to obtain a growth rate similar at high and low environmental temperatures the dietary protein content per digestible energy unit should be increased for hot conditions (fig. 1).

Key words : Rabbit, meat, dietary proteins, rearing, season.

\section{Références bibliographiques}

Bachacou J., Masson J.P., Millier C., 1981. Le programme ANVAR in: Manuel de la programmathèque statistique. Amance 81, 341-369, INRA éd., Paris.

Cheriet S., 1983. Etude comparée de lapins d'une souche sélectionnée sur la vitesse de croissance et de lapins provenant d'élevages traditionnels. Effets des équilibres alimentaires sur les performances productives. Thèse, Institut National Polytechnique de Toulouse, 119 p. + annexes. 
Eberhart S., 1980. The influence of environmental temperature on meat rabbit of different breeds. Mémoire Deuxième Congrès Mondial de Cuniculture, avril 1980, Barcelone, Vol. 2, 65-75.

INRA, 1984. L'alimentation des animaux monogastriques : porc, lapin, volailles. INRA éd., Paris, $282 \mathrm{p}$.

Lebas F., 1983 a. Bases physiologiques du besoin protéique des lapins. Analyse critique des recommandations. Cunisciences, 1, 16-27.

LeBas F., 1983 b. Engraissement des lapins à l'extérieur. Résultats préliminaires sur une année. Cuniculture, 10, 104-107.

Martina C., Damian c., Palamaru E., 1974. Retete de nutreturi combinate-granulate cu diferite nivele energoproteice pentru cresterea si ingrasarea tineretului cunicul. Lucrarile stiintifice ale Institutului de Cercetari pentru Nutritia animalia, 2, 313-322.

Ouhayoun J., 1978. Etude comparative de races de lapins différant par le poids adulte. Incidence du format paternel sur les composantes de la croissance des lapereaux issus de croisement terminal. Thèse, Université des Sciences et Techniques du Languedoc, Montpellier, 72 p. + annexes.

Ouhayoun J., Chtriet S., 1983. Valorisation comparée d'aliments à niveaux protéiques différents par des lapins sélectionnés sur la vitesse de croissance et par des lapins provenant d'élevages traditionnels. 1 - Etude des performances de croissance et de la composition du gain de poids. Ann. Zootech., 32, 257-276.

VARewyck H., Bouquet Y., 1982. Relations entre la composition tissulaire de la carcasse de lapins de boucherie et celle des principaux morceaux. Ann. Zootech., 31, 257-268. 